\title{
EDUCAÇÃO E REDUÇÃO DE DESIGUALDADES: UM ESTUDO COLABORATIVO BRASIL-PORTUGAL
}

\author{
EDUCATION AND REDUCTION OF INEQUALITY : \\ A COLLABORATIVE STUDY BRAZIL - PORTUGAL
}

\section{EDUCACIÓN Y REDUCCIÓN DE LA DESIGUALDAD : \\ UN ESTUDIO COLABORATIVO BRASIL - PORTUGAL}

\section{Eliana Perez Gonçalves de Moura ${ }^{1}$ \\ Dinora Tereza Zucchetti ${ }^{2}$ \\ Maria Antônia Belchior Ferreira Barreto ${ }^{3}$}

\begin{abstract}
RESUMO: Apresenta um texto argumentativo sobre as relações entre educação e redução de desigualdades, tomando como referência as práticas de educação desenvolvidas no Brasil e em Portugal voltadas para crianças, adolescentes e jovens socialmente vulnerabilizados. No caso brasileiro, toma o Programa Mais Educação (PME), como exemplo de política afirmativa, uma ação estratégica de articulação entre as áreas pedagógica e social, que executa ações prioritariamente dentro das escolas da rede pública e/ou na modalidade de parcerias, com ONGs e serviços comunitários executados por entidades do terceiro setor. No caso português, o enfrentamento ocorre por dentro do próprio sistema escolar, por meio das escolas de Territórios Educativos de Intervenção Prioritária (TEIPs), uma medida de política de combate aos problemas de exclusão social e escolar, em um determinado espaço geográfico. Trata-se de práticas educativas que visam à articulação de medidas locais de caráter pedagógico, psicológico e social, disponibilizando recursos humanos (mais docentes, psicólogos, mediadores, assistentes sociais, educadores sociais), além de verbas específicas. Defende que em ambos os países a ideia de vulnerabilidade é sinônimo de risco social, exigindo uma abordagem diferenciada e específica sobre essa população por meio da promoção de sua educação. Aponta algumas das diferentes formas pelas quais tais experiências educativas, na qualidade de políticas afirmativas de enfrentamento da pobreza, aproximam-se e distanciam-se em ambos os países. Encerra ressaltando que os dois modelos de intervenção, embora com características distintas, estão voltados para os mesmos segmentos populacionais reconhecidos, em ambos os países, como demandantes de ações específicas no sentido da busca por equidade social.
\end{abstract}

PALAVRAS-CHAVE: Educação. Desigualdades. Políticas Sociais. Vulnerabilidade Social. Brasil. Portugal.

ABSTRACT: This is an argumentative paper on the relationship between education and reducing inequality, taking the pedagogical practices developed in Brazil and Portugal for socially vulnerable children, teenagers and youth as its reference. In the case of Brazil, it takes Program More Education (PME) as an example of affirmative policy, a strategic action for joining the pedagogical and social areas who primarily work to execute actions within the network of public schools and/or in partnerships, with NGO's and community services executed by third-sector entities. In the case of Portugal, the confrontation happens within the school system itself, through Educational Territories of Priority Intervention (TEIPs), a policy measure for fighting the

\footnotetext{
${ }^{1}$ Doutora em Educação, Professora do Programa de Pós-Graduação em Diversidade Cultural e Inclusão Social da Universidade FEEVALE - RS - Brasil - E-mail: elianapgm@ feevale.br

${ }^{2}$ Doutora em Educação, Bolsista CNPq. Professora do Programa de Pós-Graduação em Diversidade Cultural e Inclusão Social da Universidade FEEVALE - RS - Brasil - E-mail: dinora@ feevale.br

${ }^{3}$ Doutora em Educação, Professora do Mestrados em Educação Comunitária, da Escola Superior de Educação e Ciências Sociais, do Instituto Politécnico de Leiria - Portugal - E-mail: antonia@ipleiria.pt

Recebido em: 06/07/2015 - Aprovado em: 21/10/2015.
} 
problems of social and scholastic exclusion in a set geographic area. It addresses the educational practices that are aimed toward linking the local pedagogical, psychological and social measures, making human resources (more lecturers, psychologists, mediators, social workers, social educators) available, in addition to specific funding. It maintains that in both countries, the idea of vulnerability is synonymous with social risk, demanding a differentiated approach for that population by promoting its education. The text notes some of the different ways by which such educational experiences come close to and move away from being affirmative policies for confronting poverty. It ends by highlighting that the two intervention models, despite having different qualities, are surrounded by the same sections of the population, recognized in both countries, as plaintiffs for specific action for moving toward social equality.

KEYWORDS: Education. Inequality. Social Policy. Social Vulnerability. Brazil. Portugal.

RESUMEN: Presentamos un texto argumentativo sobre las relaciones entre educación y reducción de desigualdades, teniendo como referencia las prácticas de educación desarrolladas en Brasil y en Portugal destinadas a niños, adolescentes y jóvenes socialmente vulnerables. En el caso brasileño, se toma el Programa Mais Educação (PME), como ejemplo de política afirmativa, una acción estratégica de articulación entre las áreas pedagógica y social que ejecutan acciones prioritariamente dentro de las escuelas de la red pública, o en la modalidad de alianzas con ONG y servicios comunitarios ejecutados por entidades del tercer sector. En el caso portugués, el enfrentamiento ocurre dentro del propio sistema escolar, por medio de escuelas de Territorios educativos de intervención prioritaria (TEIP), una medida de política de combate a los problemas de exclusión social y escolar, en un determinado espacio geográfico. Se trata de prácticas educativas que tienen como objetivo la articulación de medidas locales de carácter pedagógico, psicológico y social, poniendo a disposición recursos humanos (más docentes, psicólogos, mediadores, asistentes sociales, educadores sociales), además de asignaciones específicas. Sostiene que, en ambos países, la idea de vulnerabilidad es sinónimo de riesgo social, exigiendo un abordaje diferenciado y especifico sobre esa población, a través de la promoción de su educación. Señala algunas de las diferentes formas por la que tales experiencias educativas, como las políticas afirmativas de enfrentamiento de la pobreza, se aproximan y se distancian en ambos países. Finaliza resaltando que los dos modelos de intervención, si bien tienen características distintas, están destinados a los mismos segmentos poblacionales reconocidos, en ambos países, como demandantes de acciones específicas en el sentido de búsqueda por una equidad social.

PALABRAS ClAVE: Educación. Desigualdades. Políticas sociales. Vulnerabilidad social. Brasil. Portugal.

\section{INTRODUÇÃO}

A problemática abordada neste trabalho ${ }^{4}$ se inscreve em um contexto, no qual, de um lado, diversos organismos internacionais (Banco Mundo, FMI, OCDE) reconhecem a redução das desigualdades no Brasil, especialmente nas últimas duas décadas, a partir de programas sociais implementados pelo governo federal; de outro lado, a mais recente crise na Europa vem forçando uma mudança radical nas condições sociais de uma vasta parte da população em diversos países daquele continente. Os índices de desemprego não param de crescer e

\footnotetext{
${ }^{4}$ Este texto é resultado de análises e discussões desenvolvidas no âmbito de uma pesquisa de cooperação bilateral, de abordagem qualitativa, do tipo descritivo e exploratório, que tem como objetivos específicos descrever as experiências de educação desenvolvidas no âmbito das escolas de territórios educativos de intervenção prioritária (TEIPs) de uma cidade de Portugal, bem como as experiências de educação desenvolvidas no âmbito do Programa Mais Educação em uma cidade da região metropolitana de Porto Alegre/Brasil, verificando pontos de convergência e divergência presentes nessas práticas voltadas para o enfrentamento das desigualdades. A partir daí, pretende-se analisar como as experiências dessas práticas educativas repercutem sobre os sujeitos e suas famílias, no que tange às melhorias nos indicadores de acesso, permanência e aprendizagem.
} 
organismos como o Banco Mundial e o FMI pressionam os países para reduzirem o tamanho da máquina dos Estados como condição para a retomada do desenvolvimento econômico, gerando sérias consequências sobre os direitos sociais historicamente conquistados pelas populações.

Em Portugal, por exemplo, o índice de desemprego tem crescido vertiginosamente, especialmente entre os jovens, e as taxas de suicídio e violência colocam o país em estado de alerta. Um levantamento realizado recentemente (CARMO; CONSTANTE, 2010) informa que, dentre os países integrantes da União Europeia, Portugal tem permanecido entre os mais desiguais em todos os indicadores econômicos. Também as agências internacionais pressionam Portugal para a diminuição das elevadas taxas de insucesso e abandono escolares.

Entre esses dois distintos contextos, ressalta-se em comum o papel do Estado ao qual compete uma intervenção sobre a sociedade para o ordenamento da organização social e política. A definição de políticas voltadas ao combate dos níveis de desigualdades depende das escolhas efetuadas pelos governos, os quais poderão convergir suas ações mais para procedimentos político-econômicos ou para uma política social. No presente texto desenvolveremos algumas considerações sobre as práticas educativas desenvolvidas no Brasil e em Portugal voltadas para crianças, adolescentes e jovens socialmente vulnerabilizados.

\section{O CONTEXTO DE PROBLEMATIZAÇÃO}

A educação, desde sempre, ocupa a centralidade nos debates públicos sobre desigualdade. Porém, embora exista grande consenso sobre o poder transformador da educação, há importantes diferenças nas formas de abordagem do tema. De acordo com Fahel et al. (2013, p. 5), há, pelo menos, duas visões dominantes a esse respeito. Uma delas "trata a educação como modelo teórico do capital humano, colocando-a como um instrumento de redução da pobreza"; a outra abordagem situa a educação como um dos inúmeros componentes multidimensionais da desigualdade. Neste caso, trata-se de uma visão que encara a pobreza como uma barreira para a obtenção de níveis educacionais mais altos. Ambas abordagens são convergentes com os discursos predominantes no cenário brasileiro que disseminam e reforçam os pressupostos da meritocracia que considera o esforço, a disciplina e a aptidão pessoal como mérito para lograr a superação da pobreza.

Quando a questão da pobreza deixa de ser um ponto de enfrentamento da agenda política para compor a agenda econômica se produz todo um rearranjo teórico que visa oferecer sustentação ao discurso que envolve pobreza, desigualdade e classe social (MAURIEL, 2010).

No Brasil, o investimento em educação continua significando recompensas importantes em termos de remuneração, ocupação, mobilidade e status. Não obstante, de 
acordo com Fahel et al. (2013, p.19) ainda "persistem as baixas taxas de conclusão, mesmo dos níveis mais básicos de educação, bem como de acesso à educação secundária e superior". Nessa perspectiva busca-se promover a educação de crianças e jovens em uma perspectiva de redução dos riscos sociais e empoderamento das famílias, na qual a seta de causalidade mira a redução da pobreza via educação. A redução da desigualdade e de seus condicionantes seria, assim, essencial para que as pessoas possam ter oportunidades educacionais transformadoras (FAHEL, 2013).

Tanto Brasil quanto Portugal têm buscado enfrentar as questões das desigualdades sociais com ações de educação por intermédio do sistema escolar. No caso brasileiro, à escola também se associa a modalidade de educação não escolar. Em ambos os países, a ideia de vulnerabilidade é sinônimo de risco social, daí a necessidade de uma abordagem diferenciada e específica sobre essa população, seja no sentido de promover educação dela, seja no sentido de mantê-la sob vigilância a maior parte do tempo. Neste texto nossa intenção é demonstrar as diferentes formas pelas quais experiências educativas, na qualidade de políticas afirmativas de enfrentamento da pobreza, aproximam-se e distanciam-se em ambos os países.

\section{EDUCAÇÃO COMO POLÍTICA AFIRMATIVA: O CASO BRASILEIRO}

Ao confrontarmos os contextos brasileiro e português, os termos desigualdade e educação passam a designar fenômenos e ações absolutamente distintas. No que tange ao enfrentamento dessa questão, Portugal assume esse desafio por dentro do sistema escolar oficial. Mas, no Brasil, a educação não tem se restringido às práticas oferecidas pelas escolas. Especialmente, a partir da década de 1990 registrou-se uma crescente oferta da modalidade de educação do tipo não escolar, voltada a determinados segmentos da população, oferecida por ONGs e/ou entidades do Terceiro Setor em concomitância ao processo de escolarização ${ }^{5}$.

Historicamente, no Brasil algumas experiências reconhecidas como de educação integral já foram realizadas para além da mera ampliação do tempo de permanência na escola. Não obstante, tais experiências tiveram um alcance localizado, sendo que, somente a partir dos anos 2000, o MEC passou a promover debates sobre uma "educação escolar de dia inteiro" (MOLL et al., 2012). Com a proposição de um alargamento do tempo de permanência na escola, inaugurou-se no Brasil, em 2007, uma nova paisagem na educação nacional, que passou a incorporar ao cotidiano da escola as práticas de educação não escolar. A proposta de uma educação escolar de tempo integral no país está explicitamente apresentada em um conjunto de legislações (Decreto Lei $\mathrm{n}^{\circ} 7.083 / 2010$ ) que criou o Programa Mais Educação (PME). Concebido como uma política pública de Estado indutora da Educação Integral no Brasil, conta com financiamento que tem como característica

\footnotetext{
${ }^{5}$ Ver especialmente os artigos ZUCCHETTI; MOURA (2010a; 2010b); MOURA; ZUCCHETTI (2010); MOURA; ZUCCHETTI; MENEZES (2011).
} 
principal o repasse direto de recursos para a escolas e cuja adesão ao Programa se dá a partir da manifestação explícita por parte dos gestores municipais.

O Programa Mais Educação, constitui uma ação estratégica de articulação entre as áreas pedagógica e social, a partir da execução de projetos e ações prioritariamente desenvolvidos dentro das escolas da rede pública e/ou na modalidade de parcerias com ONGs e serviços comunitários executados por entidades do terceiro setor ${ }^{6}$. Uma dimensão socioeducativa caracteriza o Mais Educação como uma ação afirmativa de caráter compensatório que busca diminuir as desvantagens nos indicadores escolares das populações em desigualdades sociais. O Mais Educação constitui um programa que promove a indução da Educação Integral na rede de Ensino Público brasileiro, proporcionando a ampliação de tempo, espaços e oportunidades educacionais a crianças e adolescentes das classes populares. O Programa baseia-se na condição de formação integral do sujeito, almejando a conexão de aprendizagens da sala de aula a vivências nas oficinas.

Na prática, o Mais Educação prevê a permanência dos alunos para o mínimo de sete horas diárias, divididas entre as aulas que compõem o currículo formal e oficinas que são executadas nas escolas e/ou em espaços comunitários. As mesmas são realizadas em diversas áreas, tais como: Orientação de Estudos e Leitura, Letramento, Matemática, Dança, Judô, Capoeira, Rádio, Jornal, Teatro, todas distribuídas em macrocampos de conhecimentos. Estes se caracterizam por aglutinar áreas do conhecimento tais como: Acompanhamento Pedagógico; Comunicação, Uso de Mídias e Cultura Digital e Tecnológica; Cultura, Artes e Educação Patrimonial; Educação Ambiental, Desenvolvimento Sustentável e Economia Solidária e Criativa/Educação Econômica; Esporte e Lazer (BRASIL, 2014).

\section{POLÍticas EDUCATIVAS EM PORTUGAL: A ESCOLA COMO INDUTORA DE COESÃO SOCIAL}

No caso português, que ainda conta com a cobertura de um Estado de Bem-Estar Social, não parece haver defasagens significativas entre segmentos populacionais quanto ao acesso de diretos. Evidentemente, as mais recentes crises se fizeram sentir sobre sua população como um todo. No entanto, há muito tempo a Educação é uma política universal, cujo sistema educacional estatal, obrigatório até aos 18 anos ou à obtenção do $12^{\circ}$ ano,

\footnotetext{
${ }^{6}$ As ONGs e entidades do Terceiro Setor vêm desenvolvendo atividades na modalidade de atenção conhecida como socioeducativos em meio aberto, voltada às crianças, adolescentes e jovens socialmente vulnerabilizados. Considerando que, no caso brasileiro, as desigualdades são marcadamente socioeconômicas e, em geral, se refletem de forma mais difusas nas diferenças de acesso a direitos básicos, a parcerização com entidades da sociedade civil tem sido uma opção estratégica do Estado brasileiro, no sentido de intervir sobre os efeitos de defasagens históricas que apenas, mais recentemente, começam a ser atacadas de forma mais consistente.
} 
garante indistintamente a todas as crianças do ensino básico (de 9 anos de escolaridade) a modalidade de "escola de dia inteiro".

No que se refere às populações consideradas socialmente vulnerabilizadas, além daquelas crianças e jovens provenientes de famílias economicamente desfavorecidas, das classes mais baixas, há também outras que possuem características muito específicas: minorias pobres, residentes em zonas habitacionais marcadas pelo desemprego familiar, descendentes de imigrantes europeus e/ou africanos e que compõem um universo escolar, socialmente heterogêneo, mas onde sobressaem como eixos comuns altos índices de abandono e insucesso escolares, traduzido em múltiplas repetências. Essas crianças e jovens acabam fixados em espaços de exclusão em razão de não conseguirem acompanhar as aprendizagens no tempo previsto, por diversas causas: poucas expectativas em relação à escolarização, percursos escolares descontínuos, dificuldade na compreensão do código escolar, pertença a universos étnico-culturais com limitadas relações com a instituição escolar, entre outros fatores.

Com o objetivo de melhorar a escola básica de modo a torná-la capaz de acolher essa população, com igualdade de oportunidades, foram empreendidas medidas pelo estado português, entre elas, a criação, em 1996, dos Territórios Educativos de Intervenção Prioritária (TEIPs). Estes constituem uma medida de política educativa que prescreve uma intervenção de combate aos problemas de exclusão social e escolar, em um determinado espaço geográfico. Trata-se de práticas educativas que visam à articulação de medidas locais de caráter pedagógico, psicológico e social que acontecem no interior da escola, financiadas pelo Ministério da Educação, que disponibiliza os recursos humanos (mais docentes, psicólogos, mediadores, assistentes sociais, educadores sociais). Tais medidas devem promover o sucesso escolar e dessa forma contribuir para a diminuição das desigualdades sociais e de aprendizagem relativas a crianças, adolescente e jovens considerados socialmente vulneráveis.

Em 2006, após sofrer uma primeira avaliação, houve o relançamento do programa dos Territórios Educativos de Intervenção Prioritária (TEIP2), o qual passou especialmente a estar dirigido às

escolas ou grupamento de escolas localizados nas áreas metropolitanas de Lisboa e Porto, com elevado número de alunos em risco de exclusão social e escolar, com o objetivo de promover o sucesso educativo dos alunos pertencentes a meios particularmente desfavorecidos, através da apropriação, por parte das comunidades educativas assim caracterizadas, de recursos que lhe permitam orientar a sua ação para a reinserção escolar dos alunos (MELO, 2011, p. 163).

Mais recentemente, o Despacho Normativo 20/2012, deu sequência à implementação do Programa TEIP pretendendo alargar a medida e reforçar a autonomia das escolas para aplicação de projetos próprios. Criou-se, desse modo, o Programa TEIP3, visando a melhoria da qualidade da aprendizagem traduzida no sucesso educativo das crianças e dos jovens que se encontram em territórios marcados pela pobreza e exclusão social. Também pretendendo 
combater o abandono escolar e as saídas precoces do sistema educativo e criar condições que favoreçam a orientação educativa e a transição qualificada da escola para a vida ativa.

\section{POLÍticas E AÇÕES EdUCATIVAS NO ENFRENTAMENTO Às DESIGUALDADES SOCIAIS}

Brasil e Portugal construíram políticas e ações de educação que são, ao mesmo tempo, distintas e semelhantes. Trata-se de modos de enfrentar as questões sociais que estão substancialmente comprometidas com a redução das desigualdades, porém, se distinguem nas formas pelas quais implementam suas ações/intervenções. Ressalta-se que os dois modelos de intervenção estão voltados para os mesmos segmentos populacionais que, embora com características distintas, são reconhecidos por ambos os países como demandantes de ações específicas no sentido da busca por equidade social.

Destacando alguns pontos de comparação entre as duas realidades, podemos mencionar que enquanto o Mais Educação constitui um Programa cujas praticas educativas acontecem prioritariamente dentro da escola, as práticas de educação desenvolvidas nos TEIPs constituem a própria escola.

Na medida em que o Mais Educação se apresenta como indutor de uma política de educação integral para o país, em sua ação parece assumir funções menos vinculadas à aprendizagem e mais ligadas às finalidades de socialização e ocupação do tempo livre, aproximando-se das políticas da assistência social que, em tese, ocupam-se do controle da pobreza e dos pobres. Esse aspecto acaba produzindo a duplicação das ações que vêm sendo realizadas por ONGs e/ou instituições do Terceiro Setor, e pelo próprio serviço público no campo da assistência social.

No caso português, as escolas são convidadas a participar nos programas dos TEIPs, apresentando um projeto de candidatura que, uma vez aprovado, provoca o acesso a recursos específicos geridos autonomamente pela escola. Nesse caso, o território como espaço e tempo, sinônimo de pobreza, tem nos TEIPs a oferta e desenvolvimento de ações educativas, específicas no enfrentamento as desigualdades sociais.

Ainda que os perfis dos sujeitos-alvo de ambas as ações/intervenções educativas sejam amplamente diversificados, a forma de intervenção sobre eles mantém certa similaridade. Em Portugal, por exemplo, a intervenção sobre as crianças e adolescentes é efetuada tomando por base a territorialidade predominantemente ocupada por famílias pobres e minorias étnico-culturais. No Brasil são também crianças e jovens pobres das classes populares, em sua maioria residentes nas periferias urbanas. Ou seja, em ambos os países, o alvo das ações são sujeitos provenientes de classes subalternas, que demandam um 
posicionamento por parte do Estado no sentido de interferir no fenômeno de exclusão/inclusão social.

Finalmente, a gestão da política tomada como uma proposição indutora de uma educação que efetivamente produza igualdade de oportunidades, no Brasil é sinônima de precarização, mesmo com todos os benefícios que o PME vem oferecendo para as crianças individualmente. Por exemplo, na qualidade de programa, assenta-se no trabalho precarizado, excluindo de direitos sociais os próprios educadores que atuam como voluntários. Já em Portugal os educadores que atuam nos TEIPs têm status de professores e formação específica, revelando que a indução assume uma conotação de compromisso de Estado.

\section{CONSIDERAÇÕES FINAIS}

Em ambos os contextos, as ações de intervenção revelam os procedimentos de exclusão social gerados pelo sistema, os quais são enfrentados por governos comprometidos com as demandas das populações, investindo em política social e agindo segundo a opção de "governar aderindo à satisfação das necessidades públicas" (LOPES, 2004, p. 58). Operam um tipo de inclusão que, em geral, afirma o respeito à diversidade e expressa o reconhecimento efetivo dos efeitos desiguais e contraditórios do próprio modelo políticoeconômico.

Partindo do pressuposto de que a exclusão social constitui um fenômeno fruto de um modelo de organização social que, ao mesmo tempo em que exclui alguém de determinando espaço ou categoria, o mantém incluído em outro espaço ou categoria, entendemos que inclusão e exclusão não são conceitos opostos, mas interligados, interdependentes. Nesse sentido, parece-nos que a função das inúmeras ações de inclusão de pessoas e grupos que têm sido alvo de medidas políticas e de programas, em uma vasta gama de domínios tanto no Brasil quanto em Portugal, resume-se em inserir aqueles com menor capacidade de pressão, ou os mais humildes, em um espaço ou condição que lhes garanta o acesso aos direitos sociais.

\section{REFERÊNCIAS}

BRASIL. Ministério da Educação (MEC). Secretaria de Educação Básica (SEB). Programa mais Educação - passo a passo. Brasília/DF, 2011. Disponível em: 〈http://goo.gl/McQ1L〉. Acesso em: 06 mai. 2015.

CARMO, Renato Miguel; CONSTANTE, Frederico. Desigualdades: Portugal no mundo dos relatórios. 2010. Disponível em: 〈http://goo.gl/cK9jQl >. Acesso em: 06 jan. 2015. 
FAHEL, Murilo et al. (Org.). Desigualdades educacionais \& pobreza. Belo Horizonte, Editora PUC Minas, 2013, 394 p.

LOPES, José Rogério. Terceiro Setor: a organização das políticas sociais e a nova esfera pública. São Paulo em Perspectiva, São Paulo, SP, v. 18, n. 3, p. 57-66. 2004. Disponível em: <http://goo.gl/UBI0pa>. Acesso em: 06 jul. 2015. ISSN 1806-9452.

MAURIEL, Ana Paula. Capitalismo, políticas sociais e combate à pobreza. Ijuí: Unijuí, 2010.

MELO, Maria Benedita Portugal. Contributos para compreensão do "efeito professor TEIP": proposta de um programa de pesquisa. Sociologia: Revista da Faculdade de Letras da Universidade do Porto, Porto, v. 21, p. 159-169. 2011. Disponível em: <http://goo.gl/1436tG >. Acesso em: 06 jul. 2015. ISSN 2182-9691.

MOLL, Jaqueline (Org.) Caminhos da educação integral do Brasil: direito a outros tempos e espaços educativos. São Paulo: Penso, 2012, 504 p.

MOURA, Eliana Perez Gonçalves de; ZUCCHETTI, Dinora Tereza. Educação além da escola: abertura e acolhimento a outros saberes. Cadernos de Pesquisa, São Paulo, SP, v. 40, n. 140, p. 629-648. maio/ago. 2010. Disponível em: 〈 http://goo.gl/dQtwPP>. Acesso em: 06 jul. 2015. ISSN 1980-5314.

MOURA, Eliana Perez Gonçalves; ZUCCHETTI, Dinora Tereza; MENEZES, Magali Mendes de. Cultura e resistência: a criação do popular e o popular como criação. Revista Brasileira Estudos Pedagógicos, Brasília, DF, v. 92, n. 232, p. 663-677. set./dez. 2011. Disponível em: < http://goo.gl/bVF8NJ>. Acesso em: 06 jul. 2015. ISSN 2176-6681.

ZUCCHETTI, Dinora Tereza; MOURA, Eliana Perez Gonçalves; MENEZES, Magali Mendes de. Projetos socioeducativos. A naturalização da exclusão nos discursos de educadores. Sociedade e estado, Brasília, DF, v. 25, n. 3, p. 465-478. 2010. Disponível em: < http://goo.gl/jkYXcg>. Acesso em: 06 jul. 2015. ISSN 0102-6992.

ZUCCHETTI, Dinora Tereza, MOURA, Eliana Perez Gonçalves. Práticas socioeducativas e formação de educadores: novos desafios no campo social. Ensaio: Avaliação e Políticas Públicas em Educação. Rio de Janeiro, RJ, v. 18, n. 66, p. 09-28. jan./mar. 2010. Disponível em: < http://goo.gl/NanrMR>. Acesso em: 06 jul. 2015. ISSN 0104-4036.

Como citar este documento:

MOURA, Eliana Perez Gonçalves de; ZUCCHETTI, Dinora Tereza; BARRETO, Maria Antónia Belchior Ferreira de. Educação e redução de desigualdades: um estudo colaborativo Brasil-Portugal. ETD - Educação Temática Digital, Campinas, SP, v. 17, n. 3, nov. 2015. ISSN 1676-2592. Disponível em: <http://periodicos.sbu.unicamp.br/ojs/index.php/etd/article/view/8638238>. Acesso em: 15 dez. 2015. 